\title{
A randomized phase 2 trial of apatinib vs observation as maintenance treatment following firstline induction chemotherapy in extensive stage small cell lung cancer
}

\author{
Hao Luo ${ }^{1}$. Liang Zhang ${ }^{1} \cdot$ Bo Yang ${ }^{1} \cdot$ Yan Feng ${ }^{1} \cdot$ Yanli Xiong ${ }^{1} \cdot$ Shiheng Zhang ${ }^{1} \cdot$ Xuemei Li $^{1} \cdot$ Chengyuan Qian $^{1}$. \\ Wang Dong ${ }^{1} \cdot$ Nan Dai ${ }^{1}$
}

Received: 19 March 2019 / Accepted: 26 June 2019 / Published online: 9 August 2019

(C) The Author(s) 2019

\section{Summary}

Background The 5-year survival rate for extensive-disease small-cell lung carcinoma (ED-SCLC) is only $1 \%$. Recently, apatinib exerted promising effects on cancer patients after failure of first-line chemotherapy. Methods This study enrolled 24 ED-SCLC patients to study the efficacy and toxicity of apatinib in combination with chemotherapy and maintenance therapy. The primary endpoints were overall survival (OS) and progression-free survival (PFS). The secondary endpoints included toxicity and safety. Apatinib was given $250 \mathrm{mg}$ /day during the chemotherapy interval, and as maintenance therapy after 4-6 cycles until the patient progressed, died, or was intolerant to drug toxicity. The study further evaluated the cytotoxicity, cell-cycle arrest and apoptotic induction of apatinib in A549 and H446 cells. Results There was no difference in short-term efficacy between combined and chemotherapy groups. Long-term efficacy showed that the median PFS was 7.8 months and 4.9 months in combination and chemotherapy groups, respectively $[p=0.002$, HR(95\%CI): $0.18(0.06-0.60)]$. The median OS was 12.1 months and 8.2 months in combination and chemotherapy groups, respectively $[p=0.023, \mathrm{HR}(95 \% \mathrm{CI}): 0.38(0.16-0.90)]$. Multivariate Cox regression analysis showed that apatinib combined with chemotherapy was an independent prognostic factor for OS and PFS. The ECOG score was an independent prognostic factor affecting OS. In vitro analysis showed that apatinib inhibited cell proliferation and caused cell-cycle arrest and apoptosis. Conclusion Apatinib combination/maintenance therapy showed promising efficacy and safety to extend OS/PFS in ED-SCLC and will be a potent therapeutic option in future practice. Although the scale of this study is small, further research on large sample sizes is needed.

Keywords Apatinib $\cdot$ Maintenance therapy $\cdot$ Extensive-disease small-cell lung carcinoma $\cdot$ Apoptosis $\cdot$ Cell cycle arrest

\section{Introduction}

Small-cell lung cancer (SCLC) accounts for 15-20\% of the total number of lung cancers, and it is characterized by poor differentiation, rapid proliferation and high invasiveness. EDSCLC accounts for 60-70\% of all SCLC cases, and the 5-year survival rate for extensive-stage SCLC (ED-SCLC) patients is only $1 \%$ [1]. For half a century, the standard treatment for ED-

Electronic supplementary material The online version of this article (https://doi.org/10.1007/s10637-019-00828-x) contains supplementary material, which is available to authorized users.

Nan Dai

dn400042@hotmail.com

1 Cancer Center, Daping Hospital \& Army Medical Center of PLA, Army Medical University, Chongqing 400042, China
SCLC includes 4-6 cycles of chemotherapy cycles with platinum and etoposide. Although patients are highly sensitive to initial treatment, many patients relapse within 6 months of first-line chemotherapy and often do not respond to subsequent chemotherapy. Previous study reported that these regimens resulted in an objective tumor response rate of $73 \%$, and a median overall survival (OS) of 8-10 months [2-4]. The development of therapy to delay cancer progression and prolong survival after initial chemotherapy for SCLC is an unmet clinical need.

Tumor angiogenesis is an important factor affecting tumor growth [5]. Almost $80 \%$ of small cell lung cancer tissues have VEGF expression, and anti-angiogenesis studies on EDSCLC have been tentatively explored [6]. Bevacizumab is the most widely used anti-angiogenic drug. CALGB30306 and E3501 were two early single-arm and phase 2 clinical studies that have shown to be effective and safe in SCLC [7, 
8]. Subsequent studies, SALUTE and IFCT-0802, demonstrated that combined treatment with bevacizumab prolonged progression-free survival (PFS), but not OS $[9,10]$. In 2015, Ready et al. reported the efficacy of sunitinib in the maintenance of ED-SCLC chemotherapy [11]. The results showed that the maintenance therapy extended PFS from 2.1 months to 3.7 months $(P=0.02)$, but was ineffective for OS [11]. Two other clinical trials of pazopanib for second-line therapy of EDSCLC showed that PFS was extended nearly 2 months compared with placebo $[12,13]$. Apatinib is a VEGFR-2 inhibitor developed in China that competes for the ATP binding site of VEGFR-2 within cells and blocks the downstream signal transduction, thereby inhibiting tumor angiogenesis $[14,15]$.

We designed a prospective, randomized, concurrent clinical trial to study the clinical efficacy and toxicity of apatinib in combination with chemotherapy and maintenance therapy in ED-SCLC. For reference, it is also necessary to observe the effects of apatinib on cell viability, cell cycle and apoptosis of SCLC. This study can initially explore the molecular signaling pathway, clarify the synergistic lethality of apatinib combined with chemotherapy on SCLC, and provide a new theoretical basis for guiding clinical treatment.

\section{Materials and methods}

\section{Patient selection}

A total of 24 patients with ED-SCLC were enrolled in the study from September 2015 to February 2018. The main inclusion criteria were: 1) diagnosis of SCLC by pathological biopsy; 2) imaging staging is extensive-stage (CT or PET-CT); 3) 18-70 years old; 4) ECOG score between 0 and 2; 5) liver, kidney and bone marrow function well; and 6) patients with brain metastasis should complete whole brain radiotherapy 4 weeks or more before the first dose and without clinical symptoms. The main exclusion criteria were: 1) ECOG score $>2 ; 2$ ) estimated survival period was less than 1 month; 3 ) patients with other primary tumors. The design and clinical case data of this study were approved by the Ethics Committee of Daping Hospital\&Army Medical Center of PLA and followed the ethical requirements.

\section{Treatment}

This study was a prospective, randomized concurrent clinical controlled study (clinical trial information: NCT02875457), and the patients in the chemotherapy group received SCLC standard first-line chemotherapy as follows: cisplatin $80 \mathrm{mg} /$ $\mathrm{m} 2$ or carboplatin area under the curve of 5 on day 1 and etoposide $100 \mathrm{mg} / \mathrm{m} 2$ per day on days 1 to 3 every 21 days for four to six cycles. The chemotherapy regimen of the combined group was the same as the control group. Oral apatinib was given $250 \mathrm{mg}$ /day during the chemotherapy interval, and as maintenance therapy after $4-6$ cycles until the patient progressed, died, or was intolerant to drug toxicity. The full analysis set (FAS) included all patients who have received at least 1 cycle of treatment. The first evaluation was performed after 1 cycle ( 3 weeks) of administration, and the subsequent efficacy was evaluated every 2 cycles (6 weeks).

\section{Response and toxicity evaluation}

Patients were followed up to observe the medication, efficacy and side effects. Toxicity was evaluated and graded according to the NCI CTCAE3.0 (National Cancer Institute Common Toxicity Criteria version 3.0). Tumor shrinkage was assessed according to the RECIST1.1 (Response Evaluation Criteria in Solid Tumors guidelines version 1.1). All recorded evaluations were confirmed by independent evaluators. Evaluation procedures were performed at each cycle of treatment, including physical examination, measurement of vital signs and complete blood count. The maintenance phase was evaluated monthly.

\section{Study endpoint and follow-up}

The primary endpoints of this study were PFS and OS. The secondary endpoints included objective response rate (ORR), disease control rate (DCR), 6-months of progression-free survival rate, 12-months overall survival rate, toxicity and safety. All patients were followed up until disease progression or death. The longest follow-up period was observed as median PFS and median OS. Herein, PFS is defined as the time from the first day of treatment to the first confirmation of a patient's disease progression or death, while the OS is the time from the first day of treatment to death for any reason, follow-up failure or follow-up deadline.

\section{Cell culture, reagents and cell viability assay}

A549 and H446 cells were obtained from American Type Culture Collection (ATCC, Manassas, VA, USA). All cells were cultured in DMEM (Hyclone, Logan, UT, USA) containing 10\% fetal calf serum (Gibco, Grand Island, NY, USA) in a $37{ }^{\circ} \mathrm{C}$ humidified incubator in $5 \% \mathrm{CO}_{2}$. All experiments were conducted in the exponential phase of the cells.

The p-AKT antibody was obtained from Cell Signaling Technology (Beverly, MA, USA). $\beta$-actin and cyclinD1 antibody were obtained from abcam (Cambridge, MA, USA), and Bcl-2 and Bax antibody were purchased from Proteintech (Wuhan, China).

The CCK8 (Biosharp, Hefei, China) assay was used to evaluate the cell viability. Cells (5,000 cells per well) were seeded on 96-well culture plates and treated with 0, 10, 20, $40 \mathrm{uM}$ apatinib (Hengrui Medicine Co. Ltd., Jiangsu, China) 
for $48 \mathrm{~h}$. At the indicated time points, the supernatant was removed, and $100 \mu \mathrm{l}$ of DMEM medium containing $10 \mu \mathrm{l}$ of CCK8 was added to each well for $1.5 \mathrm{~h}$ at $37^{\circ} \mathrm{C}$. The absorbance was measured at $450 \mathrm{~nm}$ with a plate reader (Thermo Fisher Scientific, Inc., Waltham, MA, USA). The experiments were repeated three times.

\section{Analysis of apoptosis and cell cycle}

The cells were cultured with $0,10,20,40 \mu \mathrm{M}$ of apatinib for $48 \mathrm{~h}$, and apoptosis was assessed using the Annexin V-FITC kit according to the manufacturer's instructions (BioVision, Milpitas, CA, USA). Briefly, the cells were washed twice with cold PBS, digested, collected, and resuspended in binding buffer. After the Annexin V-FITC and PI were added, the cells were incubated for $15 \mathrm{~min}$ at room temperature in the darkness. Then, $200 \mu \mathrm{l}$ of binding buffer was added, and the Annexin $\mathrm{V}$ positive cells were analyzed using a FACS Calibur flow cytometry system (BD Biosciences, US). For cell-cycle assay, the cells were fixed with $70 \%$ ethanol at $-20{ }^{\circ} \mathrm{C}$ overnight, and stained with propidium iodide. The experiments were repeated three times.

\section{Western blotting analysis}

Briefly, H446 and H1688 cells were lysed with ice-cold RIPA buffer (Beyotime, Shanghai, China) for $30 \mathrm{~min}$. Proteins were separated by SDS-polyacrylamide gel electrophoresis (SDSPAGE) and transferred onto a PVDF membrane (Millipore). The membranes were sequentially blocked with skim milk, probed with primary antibodies, probed with HRPconjugated secondary antibodies, and finally developed with Pierce $^{\mathrm{TM}}$ ECL.

\section{Statistical analysis}

Statistical analyses were performed using Statistical Package for Social Sciences (SPSS) software (Version 23, SPSS, Inc., Chicago, IL, USA). Data were displayed as mean \pm standard deviation (SD). In addition, t-test analysis was performed. The Kaplan-Meier method was used to create the survival curve, and Cox proportional risk regression model was used to investigate the prognostic factors. $P<0.05$ was considered to indicate a statistically significant.

\section{Results}

\section{Patient characteristics}

A total of 24 patients were enrolled in this study to evaluate the efficacy and safety from September 2015 to February 2018. The patients were divided into 2 group, including 12 in the combined group and 12 in the chemotherapy group. The combined group included 9 males and 3 females, with an average age of 56.4 years. Among the 12 patients, 9 patients (75\%) had an ECOG (Eastern Cooperative Oncology Group) performance status score of 0 or 1 , and 2 patients $(16.7 \%)$ had brain metastases. The chemotherapy group included 9 males and 3 females, with an average age of 53.5 years. Among the 12 patients, 8 patients $(66.7 \%)$ had an ECOG performance status of 0 or 1 , and 3 patients $(25 \%)$ had brain metastases. Table 1 showed the demographics and baseline characteristics of 24 patients. There was no statistically significant difference in baseline data before treatment between the two groups, including gender, age, ECOG score and number of metastatic sites $(p>0.05)$, indicating that the baseline characteristics of the two groups were basically the same and comparable.

\section{Comparison of short-term effects of the two groups}

The response of all patients was evaluated. The objective responses were confirmed by an independent radiologist. In the combined group, one patient $(8.3 \%)$ recorded as complete response (CR), 7 patients $(58.3 \%)$ recorded as partial response (PR) with an ORR of $66.7 \%, 2$ patients $(16.7 \%)$ was stable disease (SD), and 2 patients $(16.7 \%)$ was progressive disease (PD). On the other hand, the chemotherapy group showed that 8 patients experienced PR $(66.7 \%), 2$ patients had SD and continued for more than 8 weeks, and 2 patients $(16.7 \%)$ was PD. As shown in Table 2, There was no difference in shortterm efficacy between the two groups.

\section{Comparison of long-term efficacy and prognostic factors between the two groups}

All patients died during the follow-up period until November 30, 2018. The median PFS of the two groups was 7.8 months and 4.9 months, respectively $[p=0.002$, HR (95\%CI): 0.18 (0.06-0.60)]. In the combined group, 8 patients with PR or SD had a duration of more than 6 months, and the 6-month PFS rate was $66.7 \%$, which was significantly better than $16.7 \%$ in the chemotherapy alone group, as shown in Fig. 1. The median OS of combined group and chemotherapy group was 12.1 months and 8.2 months, respectively (Fig. 2). Seven patients in the combined group had OS more than 12 months. The longest OS was 22.7 months, and the 12-month OS rate was $58.3 \%$ vs $16.7 \%$. [ $p=0.023$ HR (95\% CI):0.38 (0.160.90)]. There were significant statistical differences in PFS and OS between the two groups. Multivariate Cox regression analysis showed that apatinib combined with chemotherapy was an independent prognostic factor for OS $(p=0.020, \mathrm{HR}=0.295)$ and PFS $(p=0.005, \mathrm{HR}=$ $0.152)$ in patients. The ECOG score $(p=0.014, \mathrm{HR}=$ 4.370) was an independent prognostic factor affecting OS in patients (Table 3 ). 
Table 1 Baseline patient demographic and clinical characteristics $(n=24)$

\begin{tabular}{|c|c|c|c|c|}
\hline Characteristics & Number of patients & Apatinib combined therapy & Chemotherapy & $p$ \\
\hline Gender & & & & 1.000 \\
\hline Male & 18 & 9 & 9 & \\
\hline Female & 6 & 3 & 3 & \\
\hline Age (year) & & & & 0.682 \\
\hline$<60$ & 13 & 6 & 7 & \\
\hline$\geq 60$ & 11 & 6 & 5 & \\
\hline Average & 54.9 & & & \\
\hline ECOG performance status & & & & 0.653 \\
\hline $0-1$ & 17 & 9 & 8 & \\
\hline 2 & 7 & 3 & 4 & \\
\hline Number of the metastatic sites & & & & 0.673 \\
\hline 0 & 8 & 3 & 5 & \\
\hline 1 & 11 & 6 & 5 & \\
\hline$\geq 2$ & 5 & 3 & 2 & \\
\hline Site of metastasis & & & & 0.765 \\
\hline Bone & 8 & 4 & 4 & \\
\hline Brain & 5 & 2 & 3 & \\
\hline Liver & 3 & 2 & 1 & \\
\hline
\end{tabular}

\section{Waterfall plot of measurable lesion response}

The waterfall chart of curative effect was drawn based on the clinical data of 24 patients. It showed that the lesions were reduced in 18 patients, and a total of 16 patients obtained PR. In the combined group, one patient was $\mathrm{CR}$, and the maximum diameter of the tumor in 5 patients was reduced to more than $50 \%$. The depth of remission of combined group was significantly better than that of the chemotherapy group (Fig. 3).

\section{Safety and toxicity}

In this study, a total of 14 patients developed adverse events, and were treated symptomatically after adverse events occurred. In the combined group, there were 5 patients with grade III adverse reactions (22.7\%). Among them, hand-foot skin reaction, proteinuria, fatigue and hypertension were the most important adverse events, and the incidence was higher than that in the chemotherapy group (Table 4). Recently, several studies showed that adverse events during target therapy are associated with efficacy. Thus, the Cox proportional

Table 2 Comparison of short-term effects of the two groups

\begin{tabular}{lccccccc}
\hline & $\mathrm{n}$ & $\mathrm{CR}$ & $\mathrm{PR}$ & $\mathrm{SD}$ & $\mathrm{PD}$ & $\mathrm{ORR}$ & $\mathrm{DCR}$ \\
\hline Apatinib combined therapy & 12 & 1 & 7 & 2 & 2 & $66.7 \%$ & $83.3 \%$ \\
Chemotherapy & 12 & & 8 & 2 & 2 & $66.7 \%$ & $83.3 \%$ \\
\hline
\end{tabular}

hazards multivariate analysis was conducted to examine whether adverse events were significantly associated with PFS or OS. As shown in Table 5, adverse events including hand-foot skin reaction, hypertension, myelosuppression, proteinuria, and fatigue were not independent predictive factors of PFS and OS. This indicated that adverse events caused by apatinib-combined chemotherapy and apatinib maintenance therapy have no correlation with PFS and OS.

\section{Apatinib inhibits the proliferation of lung cancer cells}

To examine the effects of Apatinib in growth of lung cancer cells, the SCLC cell line H446 and non-small cell lung cancer (NSCLC) cell line A549 were used. Cells were incubated with 4 concentrations of Apatinib for $48 \mathrm{~h}$, and the cell viability was determined using CCK8. As shown in Fig. 4a, the growth of both H446 and A549 were suppressed by Apatinib in a concentrationdependent manner. After $48 \mathrm{~h}$ treatment, the IC50 of Apatinib in H446 and A549 cells were $18.88 \mu \mathrm{M}$ and $29.39 \mu \mathrm{M}$, respectively. At the same time, it was investigated whether apatinib enhances cisplatin- or etoposide-mediated proliferation inhibition. The cell viability of H446 and A549 cells after treatment with cisplatin and etoposide with or without $20 \mu \mathrm{M}$ apatinib was determined by CCK- 8 assay. The results indicated that cisplatin alone efficiently inhibited A549 cell proliferation, but moderately inhibited $\mathrm{H} 446$ cell proliferation. However, combined treatment with apatinib significantly enhanced cisplatin- and etoposide-mediated proliferation inhibition in H446 cells (Fig. 4b and c). Since A549 cells 
Fig. 1 Progression-free survival in patients with ED-SCLC

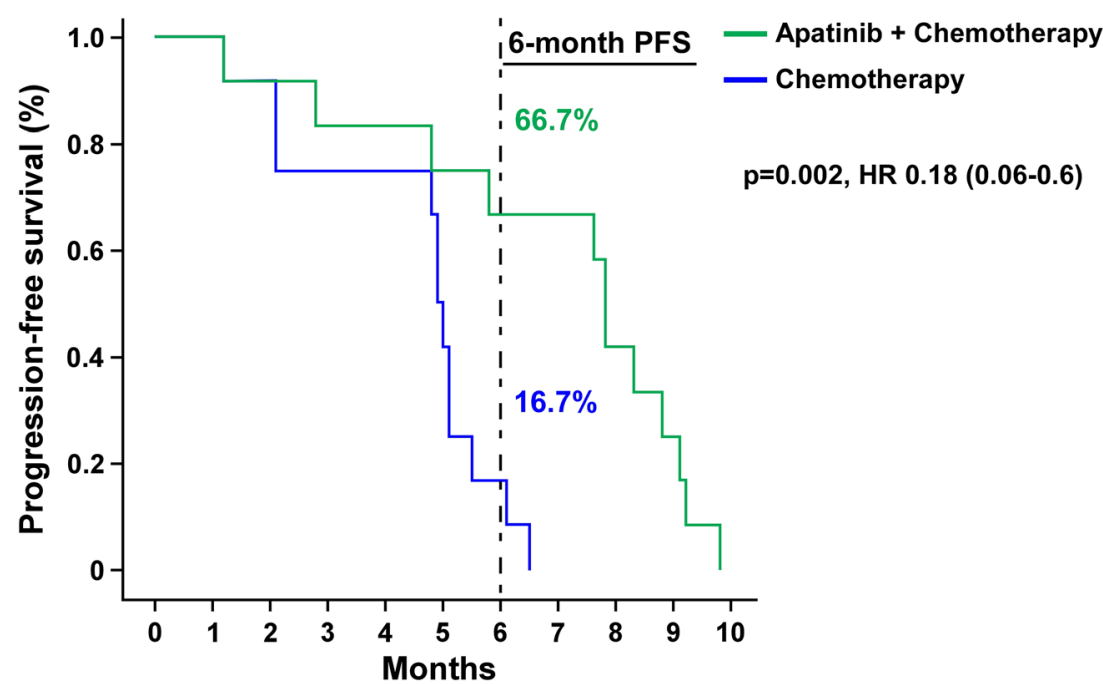

are original sensitive to cisplatin, no significant increase in inhibition was observed after combination with apatinib (Fig. 4d).

\section{Apatinib induces apoptosis and cell-cycle arrest in SCLC cells}

To evaluate the apoptotic role of apatinib in SCLC cells, cell apoptosis was determined by Annexin V-FITC and propidium iodide (PI) staining and quantified by flow cytometry. Apatinib-induced cell apoptosis significantly increased when compared with the control group (Fig. 5a). To determine whether apatinib inhibited cell proliferation by inducing cellcycle arrest, we analyzed the cell cycle distribution of apatinib-treated H446 cells. As shown in Fig. 5b, apatinib treatment induces G0/G1 cell cycle arrest and a significant decrease in the G2 and S population (Fig. 5b). After $48 \mathrm{~h}$ of treatment of apatinib, the key apoptosis indicators Bax and Bcl-2 increased and decreased, respectively (Fig. 5c). To elucidate the mechanisms, we determined the expression level of cyclin D1, a G0/G1-phase-related protein. As shown in Fig. $5 \mathrm{c}$, the expressions of cyclin D1 decreased after treatment with apatinib. In addition, downstream targets of the VEGFR2 signaling pathway were analyzed. The level of phosphorylated AKT was reduced in apatinib-treated SCLC cells (Fig. 5c). All the data suggested that apatinib induced apoptosis and G0/G1 cell cycle arrest and inhibited the VEGFR2 signaling pathway.

\section{Discussion}

Apatinib is a highly selective tyrosine kinase inhibitor of VEGFR2 and exerts a promising antitumoral effect in various tumors. Our clinical trial confirmed that apatinib is effective
Fig. 2 Overall survival in patients with ED-SCLC

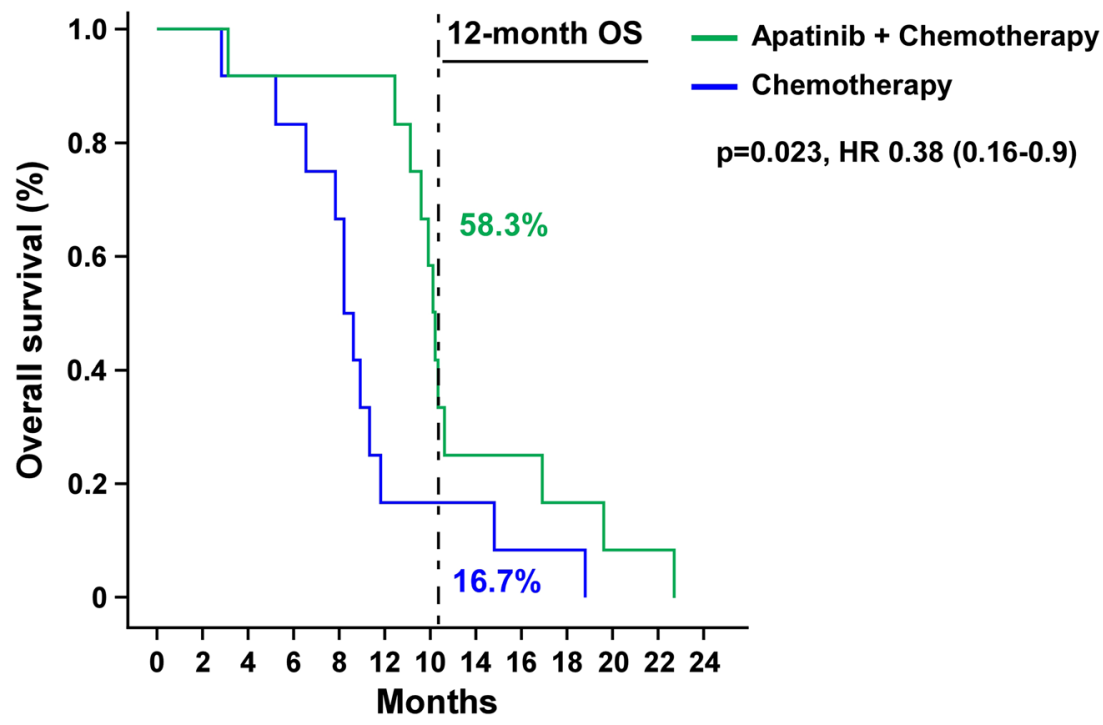


Table 3 Multivariate Cox regression analysis of PFS and OS in SCLC patients

\begin{tabular}{|c|c|c|c|c|}
\hline \multirow[t]{2}{*}{ Factor } & \multicolumn{2}{|l|}{ PFS } & \multicolumn{2}{|l|}{ OS } \\
\hline & $\mathrm{HR}(95 \% \mathrm{CI})$ & $p$ & $\mathrm{HR}(95 \% \mathrm{CI})$ & $p$ \\
\hline Age & $0.705(0.275-1.810)$ & 0.468 & $0.896(0.316-2.539)$ & 0.836 \\
\hline Gender & $1.852(0.697-4.930)$ & 0.216 & $2.342(0.750-7.310)$ & 0.143 \\
\hline ECOG & $2.119(0.747-6.007)$ & 0.158 & $4.370(1.345-14.198)$ & 0.014 \\
\hline Site of metastasis & $1.147(0.581-2.265)$ & 0.693 & $1.173(0.609-2.259)$ & 0.634 \\
\hline Apatinib combined therapy & $0.152(0.041-0.563)$ & 0.005 & $0.295(0.105-0.827)$ & 0.020 \\
\hline
\end{tabular}

Apatinib combined with chemotherapy was an independent prognostic factor for OS and PFS in patients. The ECOG score was an independent prognostic factor affecting OS in patients. $\boldsymbol{p}<\mathbf{0 . 0 5}$ and safe in the treatment of ED-SCLC, and can prolong the duration of clinical benefit of patients. In addition, this study further demonstrated that apatinib can induce SCLC cell apoptosis and G0/G1 cell cycle arrest and affect VEGFR2 signaling pathway.

There is no standard protocol for maintenance therapy of SCLC. Due to the high toxicity of chemotherapeutic drugs, we expect anti-angiogenic agents to play an important role in maintenance therapy. Based on the expression of high microvessel density and vascular endothelial growth factor in nearly $80 \%$ of SCLC cases, angiogenesis is critical in SCLC [16]. In 2007, a phase 2 clinical trial of thalidomide as a maintenance therapy for SD-SCLC indicated that median survival from time of initiation of induction chemotherapy was 12.8 months (95\% CI: 10.1-15.8 months) and 1-year survival of $51.7 \%$ (95\% CI: $32.5-67.9 \%$ ). When administrated as maintenance therapy for ED-SCLC after induction chemotherapy, $200 \mathrm{mg}$ of thalidomide per day was well tolerated. However, the subsequent phase III clinical study found that thalidomide combined with chemotherapy shortened patient survival and increased the risk of thrombosis [17]. Moreover, studies on the application of imatinib and vandetanib in SCLC found that the addition of these drugs cannot bring survival benefits [18]. Another phase 2 study of sunitinib found that although the benefits of OS were not achieved, but the use of sunitinib extended PFS (median PFS was 3.7 months vs 2.8 months and median OS was 9 months vs 6.9 months) [11]. There are also reports of immunotherapy for SCLC. CheckMate 331 study found that Nivolumab did not show superior efficacy in SCLC patients who have relapsed after first-line chemotherapy. But IMpower 133 study found combined atezolizumab for the first-line chemotherapy of EDSCLC showed a significantly longer OS and PFS than chemotherapy alone [19]. Other studies found that the efficacy of apatinib in the treatment of ED-SCLC after two or more chemotherapy failures is effective and safe [20, 21].

The results of this clinical study showed that apatinib combined with EP regimen significantly improved OS and PFS in ED-SCLC patients compared with chemotherapy alone. The median PFS was 7.8 months and 4.9 months, respectively $[p=0.002$, HR $(95 \%$ CI): $0.18(0.06-0.60)]$. The median OS of the two groups was 12.1 months and 8.2 months,
Fig. 3 Waterfall plot of measurable lesion response

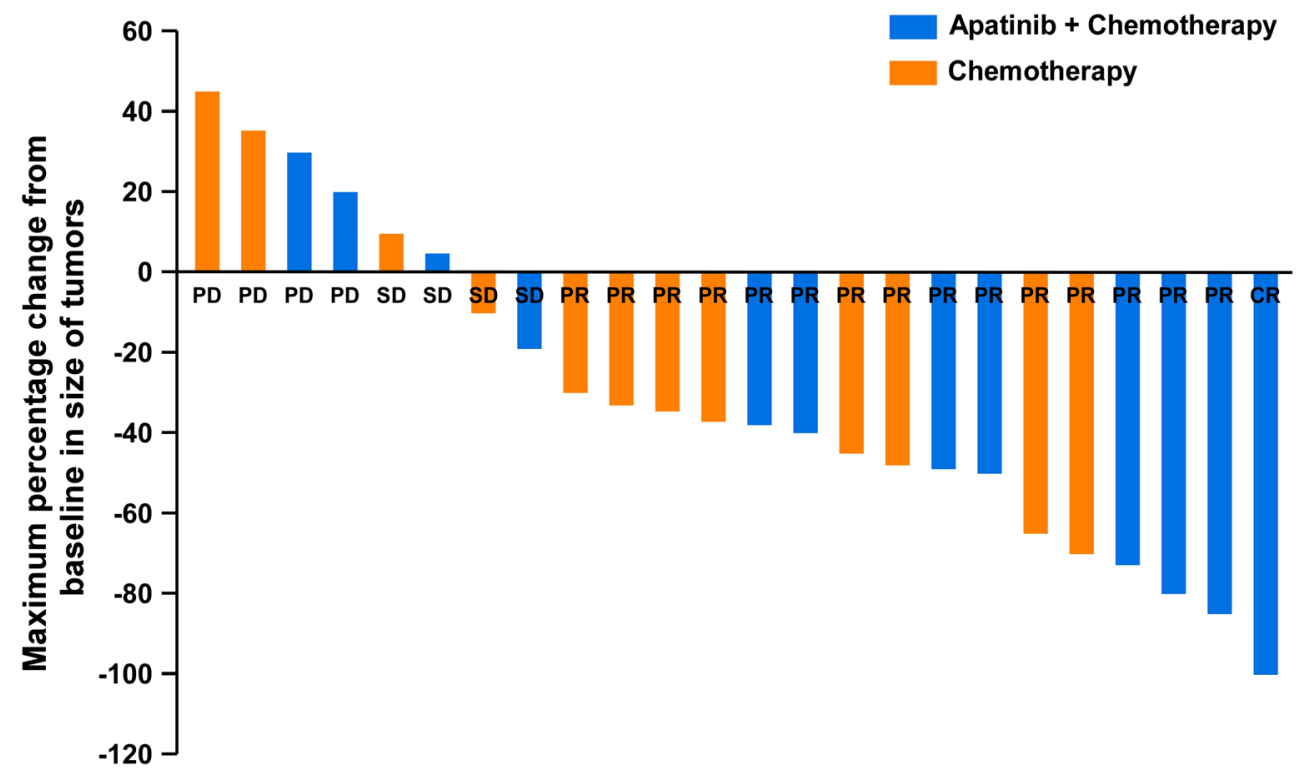


Table 4 The occurrence of adverse events

\begin{tabular}{|c|c|c|c|c|c|}
\hline \multirow[t]{2}{*}{ Adverse events } & \multicolumn{2}{|c|}{$\begin{array}{l}\text { Apatinib combined therapy } \\
N=12\end{array}$} & \multicolumn{2}{|c|}{$\begin{array}{l}\text { Chemotherapy } \\
N=12\end{array}$} & \multirow[t]{2}{*}{$P$} \\
\hline & Type I-II & Type III-IV & Type I-II & Type III-IV & \\
\hline hand-foot skin reaction & $4(33.3 \%)$ & $1(8.3 \%)$ & $1(8.3 \%)$ & 0 & 0.624 \\
\hline Hypertension & $3(25.0 \%)$ & $2(16.7 \%)$ & 0 & 0 & \\
\hline Myelosuppression & $2(9.1 \%)$ & 0 & $3(25.0 \%)$ & $1(8.3 \%)$ & 0.350 \\
\hline proteinuria & $1(8.3 \%)$ & $1(8.3 \%)$ & 0 & 0 & \\
\hline Oral mucosal ulcer & $2(9.1 \%)$ & 0 & $1(8.3 \%)$ & 0 & \\
\hline Fatigue & $4(33.3 \%)$ & $1(8.3 \%)$ & $2(16.7 \%)$ & $1(8.3 \%)$ & 0.673 \\
\hline Diarrhea & $1(8.3 \%)$ & 0 & $1(8.3 \%)$ & 0 & \\
\hline Total case number & 15 & 5 & 8 & 2 & 0.760 \\
\hline
\end{tabular}

respectively. The respective OS rate at 12 months was $58.3 \%$ vs $16.7 \%$ [ $p=0.023 \mathrm{HR}(95 \% \mathrm{CI})$ : $0.38(0.16-0.90)]$. Statistical analysis suggested that the PFS and OS of two groups has significant statistical differences. In this study, 14 patients suffered from various adverse events, and the incidence of adverse events was $58.3 \%$. Among them, 5 patients $(33.3 \%)$ in the combined group had grade III or above adverse reactions, including hand-foot skin reactions, proteinuria and hypertension. In consistent to our study, Shi et al. [22]. found that in the treatment of advanced NSCLC with apatinib, the incidence of adverse events was higher in the apatinib group, mainly proteinuria, hypertension and hand-foot syndromes. Multivariate Cox regression analysis showed that apatinib combined with chemotherapy was an independent prognostic factor for OS and PFS in patients. This suggests that apatinib may be a clinical option for combination chemotherapy or single-agent maintenance therapy for patients with good clinical physical strength, low tumor burden, and lack of effective treatment and maintenance. Apatinib can prolong the patient's sustained clinical benefit, but current evidence is insufficient. Anti-angiogenic drugs are more at risk for bleeding and hypertension, and the benefits and risks need to be fully weighed. In our in vitro study, apatinib significantly enhanced cisplatin- or etoposide-mediated proliferation inhibition in H446 cells when compared with cells treated with cisplatin alone. In addition, our data showed that apatinib can induce cell apoptosis and G0/G1cell cycle arrest and affect
VEGFR2 signaling pathway. Liu et al. [23]. reported that apatinib could promote autophagy and apoptosis through VEGFR2/STAT3/BCL-2 signaling in osteosarcoma. The same study by Peng et al. [24] indicated that apatinib could inhibit VEGF signaling and promote apoptosis of intrahepatic cholangiocarcinoma.

Adverse events are often observed in cancer patients undergoing therapeutic treatment. Recently, several studies showed that adverse events during target therapy were associated with efficacy, such as cetuximab and panitumumab in colorectal cancer [25], cetuximab in advanced head and neck cancer [26], sunitinib and sorafenib in metastatic renal cell carcinoma [27], and sunitinib in metastatic renal cell carcinoma [28]. In this study, however, adverse events were not associated with efficacy in ED-SCLC patients treated with apatinib-combined and maintenance therapy. These EDSCLC patients were less likely to develop these adverse effects. Since the poor treatment outcome was not related to adverse events, in addition to active supportive care in the future, a threshold for increasing the therapeutic dose may be set. However, it must be understood that increasing the therapeutic dose of apatinib may be a double-edge sword because it may simultaneously increase the efficacy and worse OS/PFS. Thus, we will further explore and strengthen this part in future studies.

Studies have shown that angiogenesis is a key mechanism of tumor growth and an important step in tumor
Table 5 The Cox proportional hazards multivariate analysis for PFS and OS of SCLC patients

\begin{tabular}{llllll}
\hline Adverse events & Grouping & OR(95\%CI) for PFS & $P$ value & OR(95\%CI) for OS & $P$ value \\
\hline Hand-foot skin reaction & Yes/no & $0.797(0.148-4.287)$ & 0.791 & $0.127(0.013-1.270)$ & 0.079 \\
Hypertension & Yes/no & $1.760(0.342-9.045)$ & 0.498 & $2.857(0.390-20.940)$ & 0.302 \\
Myelosuppression & Yes/no & $1.943(0.253-14.925)$ & 0.523 & $0.040(0.001-1.852)$ & 0.100 \\
proteinuria & Yes/no & $0.142(0.010-1.919)$ & 0.142 & $0.203(0.017-2.398)$ & 0.206 \\
Fatigue & Yes/no & $0.538(0.112-2.580)$ & 0.439 & $0.751(0.150-3.761)$ & 0.728 \\
\hline
\end{tabular}

$C I$, Confidence interval; OR, Odds ratio; OS, Overall survival; PFS, Progression-free survival 

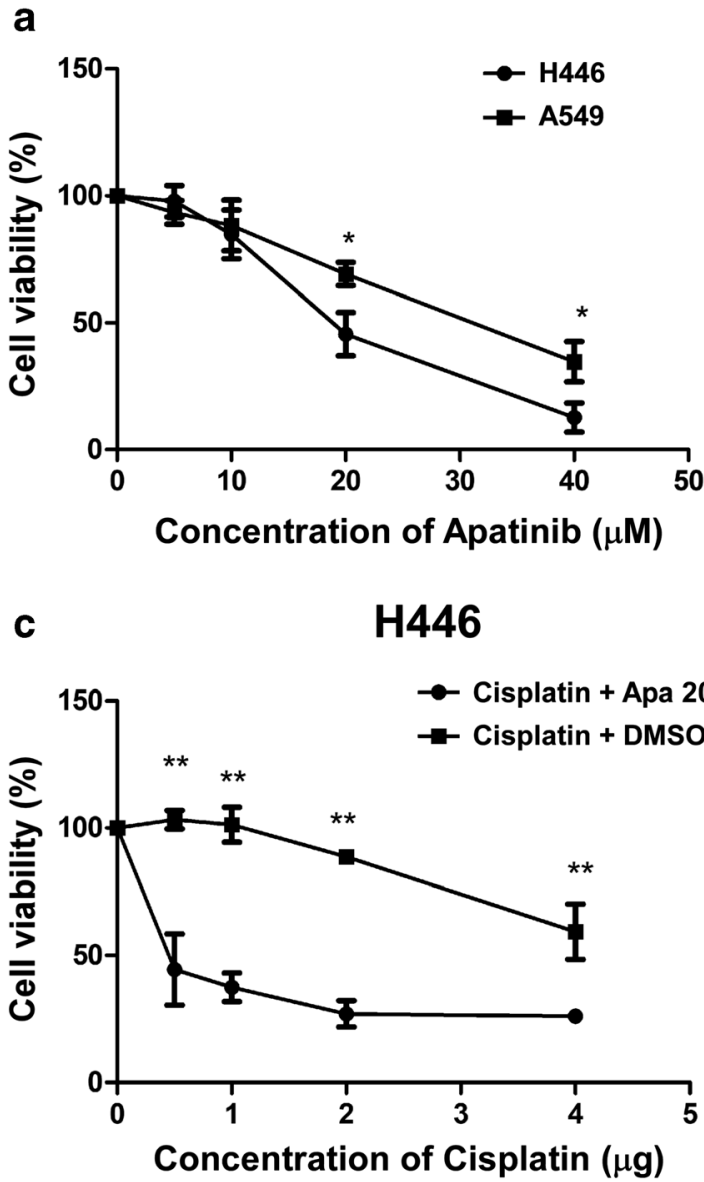

Fig. 4 Apatinib inhibits the proliferation of lung cancer cells and enhances the inhibitory effect of cisplatin on SCLC cells. a: Apatinib inhibited the growth of A549 and H446 cancer cells in a concentrationdependent manner. b: The viability of $\mathrm{H} 446$ cells was measured after treatment with $20 \mu \mathrm{M}$ apatinib or DMSO for $48 \mathrm{~h}$ in combination with

progression, invasion and metastasis [29]. VEGF/ VEGFR2 is an important signaling pathway for tumor angiogenesis, in which VEGF has the ability to enhance tumor invasion and survival, and can play the role of cancer stem cells. On the other hand, VEGF also has the function of recruiting regulatory $\mathrm{T}$ cells, which can inhibit the body's anti-tumor immune response. VEGFR2 is a transmembrane protein, and VEGF specifically binds to the extracellular domain of VEGFR2 to activate mitogenactivated protein kinase (MAPK), phosphatidylinositol 3kinase (PI3K), protein kinase $\mathrm{C}$ (PKC), focal adhesion kinase (FAK) and other downstream signaling pathways. Activation including cell proliferation, migration, permeability and survival plays a primary role in angiogenesis and production. Therefore, anti-angiogenic targeted drugs are the hotspots in recent years for the treatment of NSCLC. Apatinib is highly selective tyrosine kinase inhibitor of VEGFR2. When targeting to VEGFR-2, the tyrosine kinase activity of the cells was inhibited, resulting in the inhibition of VEGF/VEGFR-2 b $\quad \mathrm{H446}$
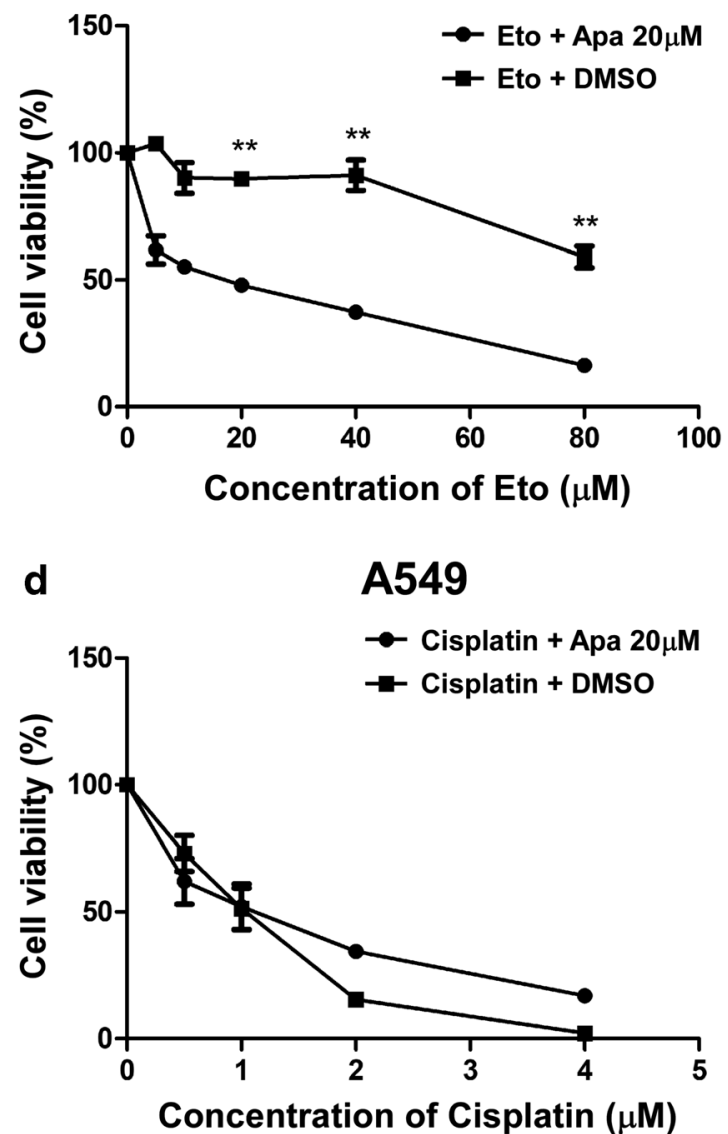

various concentrations of Eto. c: The viability of $\mathrm{H} 446$ cells was measured after treatment with $20 \mu \mathrm{M}$ apatinib or DMSO for $24 \mathrm{~h}$ in combination with various concentrations of cisplatin. $\mathbf{d}$ :The viability of A549 cells was measured after treatment with $20 \mu \mathrm{M}$ apatinib or DMSO for $48 \mathrm{~h}$ in combination with various concentrations of cisplatin

signaling pathway and subsequent inhibition of tumor angiogenesis and tumor progression. The process of inhibiting tumor angiogenesis can effectively reduce tumor progression and metastasis [30].

In the past few years, lung cancer tumors with very poor prognosis have only achieved minor therapeutic success. The main reason for most chemotherapy failures is the development of chemoresistance. Most lung cancer patients will eventually develop resistance to the chemotherapeutic agents which they exposed to, even with good initial response. In addition to active efflux of the chemotherapeutic agent from tumor cells, hypoxic tumor microenvironment and hypoxia-mediated upregulation of VEGF play an important role in the hypervascularization, forming new blood vessels to supply nutrient and oxygen for tumor progression and recurrence. Since many therapeutic drugs cannot increase the overall survival after the failure of chemotherapy, VEGF-targeting by apatinib can be combined with traditional treatment modalities to 
a

PI
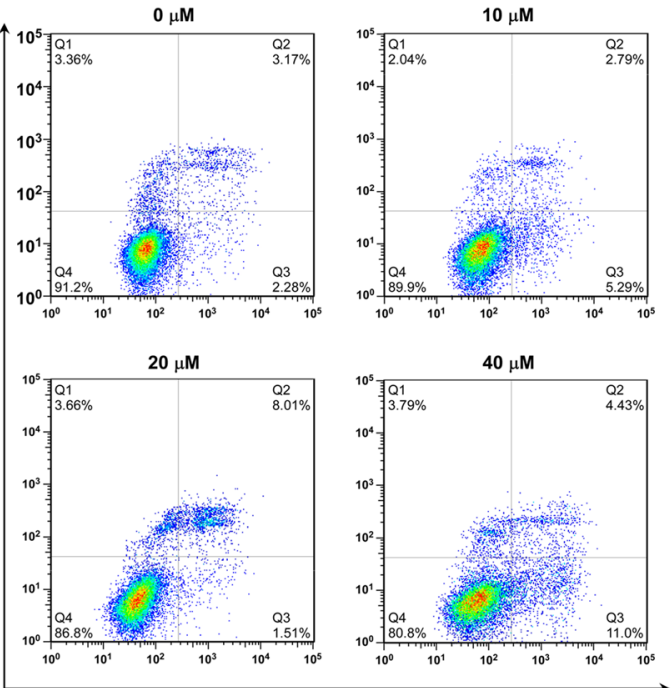

Annexin-FITC

b
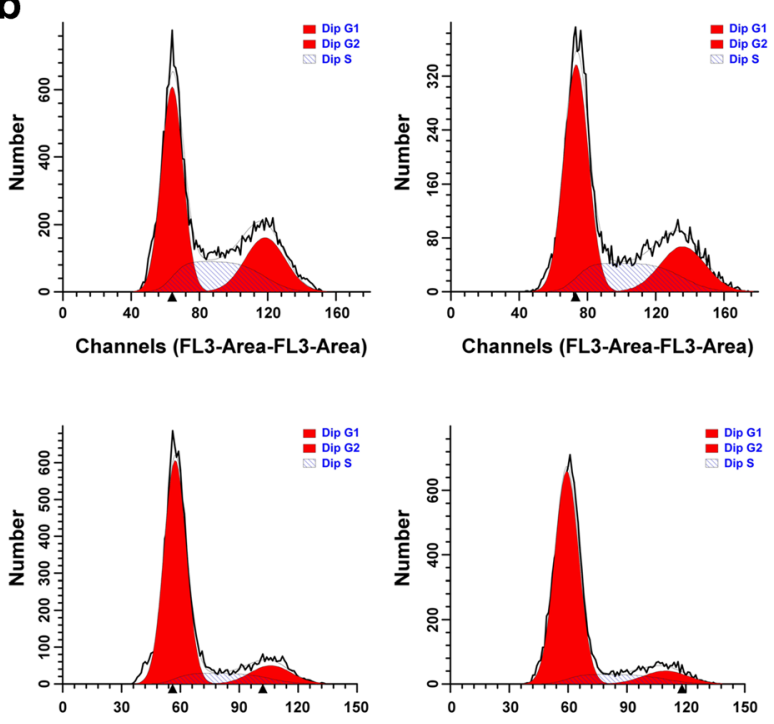

Channels (FL3-Area-FL3-Area)

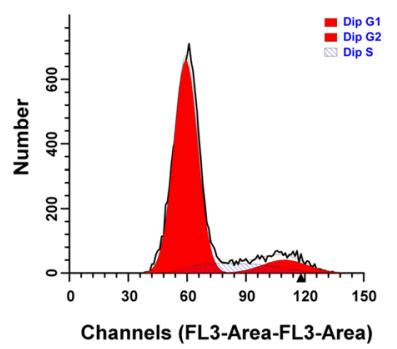

C
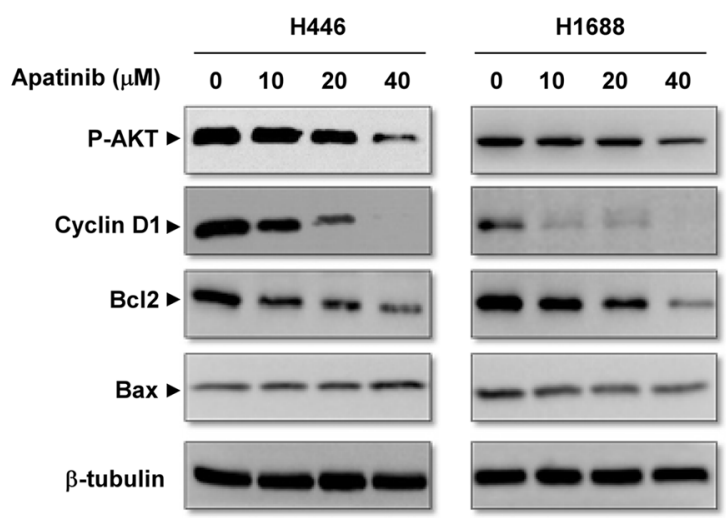

Fig. 5 Apatinib induces apoptosis and cell-cycle arrest in SCLC. a: Apoptosis rates of $\mathrm{H} 446$ cells after incubating $0,10,20$, or $40 \mu \mathrm{M}$ apatinib for $48 \mathrm{~h}$ were determined by double staining of Annexin V and $\mathrm{PI}$ and quantified by flow cytometry. $\mathbf{b}$ : Apatinib caused G0/G1 cell cycle

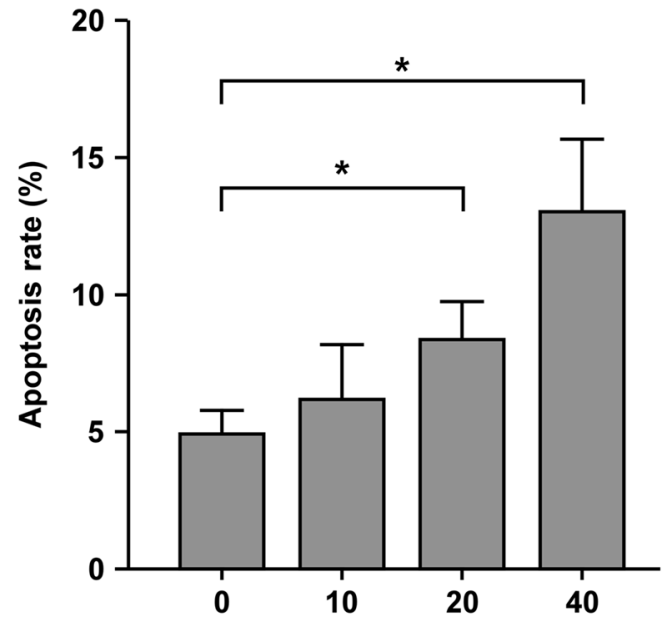

Apatinib concentration $(\mu \mathrm{M})$

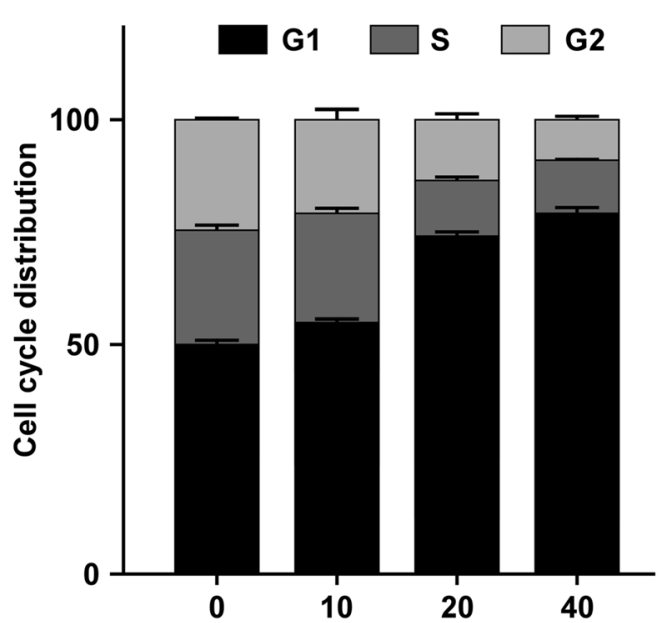

Apatinib concentration $(\mu \mathrm{M})$ arrest in $\mathrm{H} 446$ cells. Cell cycle were analyzed by flow cytometry. c: The expressions of $\mathrm{p}-\mathrm{AKT}$, cyclin $\mathrm{D} 1, \mathrm{Bcl}-2$ and Bax were determined by Western blotting analysis. Beta-tubulin was used as an internal loading control 
ensure maximum effectiveness. In order to reduce chemoresistance, continuous use of low doses of apatinib may inhibit VEGF-mediated angiogenesis (the basic function of apatinib). In particular, apatinib was able to prevent multidrug resistance (MDR) of cancer cells against other conventional chemotherapeutic drugs by inhibiting ABCB1 and ABCG2-mediated drug export [31]. Increased accumulation of doxorubicin was found in the apatinib-treated MDR cells. In addition, the effect of apatinib maintenance on prolonging OS may be due to the promotion of tumor cell apoptosis and cell cycle arrest (Figs. 4 and 5). Thus, it is the possible reason that apatinib maintenance therapy combined with chemotherapy can lead to a significant prolongation of overall survival and progression-free survival in ED-SCLC patients.

There was no breakthrough in patients with ED-SCLC, with a median OS of 8-10 months. The main reason may be that EDSCLC produces strong drug resistance and tumor immune microenvironment, when it progresses after first-line treatment, resulting in extremely poor efficacy of second-line treatment. Although apatinib showed advantage in the tumor MDR, the problem of tumor immune microenvironment was not improved. Recently, checkpoint blockade immunotherapy received promising attention in the treatment for ED-SCLC. Although phase II [32] and III [33] trial showed no significant differences between the control and ipilimumab (anti-CTLA4) groups, PD-L1 antibody (nivolumab, pembrolizumab, atezolizumab) showed its safety and clinical efficacy [34-37]. Furthermore, recent clinical studies demonstrated that combined treatment with pembrolizumab and chemotherapy showed significantly benefit in advanced NSCLC $[38,39]$, advanced or metastatic platinumrefractory urothelial cancer [40], and advanced gastric or gastroesophageal junction adenocarcinoma [41]. Considering the results of KEYNOTE-024 and 189 [42, 43], the introduction of immunotherapy as a firstline therapy may have a beneficial long-term effect on the results. The future of ED-SCLC treatment may combine PDL1 (e.g. pembrolizumab) and chemotherapy to maximize efficacy, and followed by apatinib maintenance therapy to eliminate tumor MDR effect.

In conclusion, our study showed that apatinib has significant efficacy and high safety in the treatment of ED-SCLC. It can clinically extend the patient's sustained duration, and it can be further studied and applied in clinical practice. Although the sample size of this study is small, further studies with larger sample size are needed.

Authors' contributions LH conceptually designed the experiments, analyzed and interpreted the data, and drafted the manuscript. ZL performed the cell experiments and study the possible mechanism. YB performed part of the experiments and edited the manuscript. FY, XY and Li XM performed the clinical studies and data acquisition. ZS evaluated the safety and efficacy. DN developed the concept for this study and provided technical support and approval of the investigation.
Funding This work was supported by the National Natural Science Foundation of China (No. 8167102678 and No. 81502241) and by the special project of social undertakings and social security innovation in Chongqing.

\section{Compliance with ethical standards}

Conflict of interest Luo Hao, Zhang Liang, Yang Bo, Feng Yan, Xiong Yanli, Zhang Shiheng, Li Xuemei, Qian Chengyuan, Dong Wang and Dai Nan declare that they have no conflict of interest.

Ethical approval All procedures performed in studies involving human participants were in accordance with the ethics committee of Daping Hospital \& Army Medical Center of PLA and with the 1964 Helsinki declaration and its later amendments or comparable ethical standards.

Informed consent Informed consent was obtained from all individual participants included in the study.

Open Access This article is distributed under the terms of the Creative Commons Attribution 4.0 International License (http:// creativecommons.org/licenses/by/4.0/), which permits unrestricted use, distribution, and reproduction in any medium, provided you give appropriate credit to the original author(s) and the source, provide a link to the Creative Commons license, and indicate if changes were made.

\section{References}

1. Liu B, Qin J, Zhou J (2017) Advances in the treatment of relapsed small cell lung cancer. Zhongguo Fei Ai Za Zhi 20(3):192-198. https://doi.org/10.3779/j.issn.1009-3419.2017.03.08

2. Thatcher N (2002) New drugs in small cell lung cancer. Suppl Tumori 1(4):S26-S27

3. Lara PN Jr, Natale R, Crowley J, Lenz HJ, Redman MW, Carleton JE, Jett J, Langer CJ, Kuebler JP, Dakhil SR, Chansky K, Gandara DR (2009) Phase III trial of irinotecan/cisplatin compared with etoposide/cisplatin in extensive-stage small-cell lung cancer: clinical and pharmacogenomic results from SWOG S0124. J Clin Oncol 27(15):2530-2535. https://doi.org/10.1200/JCO.2008.20.1061

4. Horn L, Castellanos EL, Johnson DH (2011) Update on new drugs in small cell lung cancer. Expert Opin Investig Drugs 20(4):441445. https://doi.org/10.1517/13543784.2011.553185

5. Folkman J (2002) Role of angiogenesis in tumor growth and metastasis. Semin Oncol 29(6 Suppl 16):15-18. https://doi.org/10. 1053/sonc. 2002.37263

6. Rha JED, Lai WS (2004) Survival in small cell lung cancer is independent of tumor expression of VEGF and COX-2. Anticancer Res 24:2367-2374

7. Horn L, Dahlberg SE, Sandler AB, Dowlati A, Moore DF, Murren JR, Schiller JH (2009) Phase II study of cisplatin plus etoposide and bevacizumab for previously untreated, extensive-stage small-cell lung cancer: eastern cooperative oncology group study E3501. J Clin Oncol 27(35):6006-6011. https://doi.org/10.1200/JCO.2009. 23.7545

8. Ready NE, Dudek AZ, Pang HH, Hodgson LD, Graziano SL, Green MR, Vokes EE (2011) Cisplatin, irinotecan, and bevacizumab for untreated extensive-stage small-cell lung cancer: CALGB 30306, a phase II study. J Clin Oncol 29(33):4436-4441. https://doi.org/10.1200/JCO.2011.35.6923

9. Spigel DR, Townley PM, Waterhouse DM, Fang L, Adiguzel I, Huang JE, Karlin DA, Faoro L, Scappaticci FA, Socinski MA (2011) Randomized phase II study of bevacizumab in combination 
with chemotherapy in previously untreated extensive-stage smallcell lung cancer: results from the SALUTE trial. J Clin Oncol 29(16):2215-2222. https://doi.org/10.1200/JCO.2010.29.3423

10. Tiseo M, Boni L, Ambrosio F, Camerini A, Baldini E, Cinieri S, Brighenti M, Zanelli F, Defraia E, Chiari R, Dazzi C, Tibaldi C, Turolla GM, D'Alessandro V, Zilembo N, Trolese AR, Grossi F, Riccardi F, Ardizzoni A (2017) Italian, multicenter, phase III, randomized study of cisplatin plus etoposide with or without bevacizumab as first-line treatment in extensive-disease small-cell lung cancer: the GOIRC-AIFA FARM6PMFJM trial. J Clin Oncol 35(12):1281-1287. https://doi.org/10.1200/JCO.2016.69.4844

11. Ready NE, Pang HH, Gu L, Otterson GA, Thomas SP, Miller AA, Baggstrom M, Masters GA, Graziano SL, Crawford J, Bogart J, Vokes EE (2015) Chemotherapy with or without maintenance Sunitinib for untreated extensive-stage small-cell lung Cancer: a randomized, double-blind, placebo-controlled phase II studyCALGB 30504 (Alliance). J Clin Oncol 33(15):1660-1665. https://doi.org/10.1200/jco.2014.57.3105

12. Koinis F, Agelaki S, Karavassilis V, Kentepozidis N, Samantas E, Peroukidis S, Katsaounis P, Hartabilas E, Varthalitis II, Messaritakis I, Fountzilas G, Georgoulias V, Kotsakis A (2017) Second-line pazopanib in patients with relapsed and refractory small-cell lung cancer: a multicentre phase II study of the Hellenic oncology research group. Br J Cancer 117(1):8-14. https://doi.org/10.1038/bjc. 2017.137

13. Sun JM, Lee KH, Kim BS, Kim HG, Min YJ, Yi SY, Yun HJ, Jung SH, Lee SH, Ahn JS, Park K, Ahn MJ (2018) Pazopanib maintenance after first-line etoposide and platinum chemotherapy in patients with extensive disease small-cell lung cancer: a multicentre, randomised, placebo-controlled phase II study (KCSG-LU12-07). Br J Cancer 118(5):648-653. https://doi.org/10.1038/bjc.2017.465

14. 叔选, 李进 (2015) 阿帕替尼治疗胃癌的临床应用专家共识. 临床肿瘤学 杂志 20 (9):841-847

15. 杜娟, 刘宝瑞（2016）阿帕替尼治疗二例晚期难治性胃癌的临床观察. 中华肿瘤杂志 38 (8) :636-638

16. Lucchi M, Mussi A, Fontanini G, Faviana P, Ribechini A, Angeletti CA (2002) Small cell lung carcinoma (SCLC): the angiogenic phenomenon. Eur J Cardiothorac Surg 21(6):1105-1110

17. Lee SM, Woll PJ, Rudd R, Ferry D, O'Brien M, Middleton G, Spiro S, James L, Ali K, Jitlal M, Hackshaw A (2009) Anti-angiogenic therapy using thalidomide combined with chemotherapy in small cell lung cancer: a randomized, double-blind, placebo-controlled trial. J Natl Cancer Inst 101(15):1049-1057. https://doi.org/10. 1093/jnci/djp200

18. Arnold AM, Seymour L, Smylie M, Ding K, Ung Y, Findlay B, Lee CW, Djurfeldt M, Whitehead M, Ellis P, Goss G, Chan A, Meharchand J, Alam Y, Gregg R, Butts C, Langmuir P, Shepherd F, National Cancer Institute of Canada Clinical Trials Group Study BR (2007) Phase II study of vandetanib or placebo in small-cell lung cancer patients after complete or partial response to induction chemotherapy with or without radiation therapy: National Cancer Institute of Canada clinical trials group study BR.20. J Clin Oncol 25(27):4278-4284. https://doi.org/10.1200/JCO.2007.12.3083

19. Horn L, Mansfield AS, Szczesna A, Havel L, Krzakowski M, Hochmair MJ, Huemer F, Losonczy G, Johnson ML, Nishio M, Reck M, Mok T, Lam S, Shames DS, Liu J, Ding B, LopezChavez A, Kabbinavar F, Lin W, Sandler A, Liu SV Group IMS(2018) First-line Atezolizumab plus chemotherapy in extensive-stage small-cell lung Cancer. N Engl J Med 379:2220 2229. https://doi.org/10.1056/NEJMoa1809064

20. Hong WLH, Jin X (2017) P1.07-053 apatinib for chemotherapyrefractory extensive stage SCLC: results from a single-center retrospective study. J Thorac Oncol 12:S729

21. Yutao Liu XH, Zhou S (2017) P3.04-007 - a prospective study of Apatinib in advanced small cell lung cancer patients failed from two or more lines of chemotherapy. Abstract WCLC
22. SHI Mingwei WS, Zhenwu XU (2017) Effect of apatinib on the advanced non-small cell lung cancer. J Clin Pathol Res 37(9):1880 1886

23. Liu K, Ren T, Huang Y, Sun K, Bao X, Wang S, Zheng B, Guo W (2017) Apatinib promotes autophagy and apoptosis through VEGFR2/STAT3/BCL-2 signaling in osteosarcoma. Cell Death Dis 8(8):e3015. https://doi.org/10.1038/cddis.2017.422

24. Peng H, Zhang Q, Li J, Zhang N, Hua Y, Xu L, Deng Y, Lai J, Peng Z, Peng B, Chen M, Peng S, Kuang M (2016) Apatinib inhibits VEGF signaling and promotes apoptosis in intrahepatic cholangiocarcinoma. Oncotarget 7(13):17220-17229. https://doi.org/10. 18632/oncotarget.7948

25. Petrelli F, Borgonovo K, Barni S (2013) The predictive role of skin rash with cetuximab and panitumumab in colorectal cancer patients: a systematic review and meta-analysis of published trials. Target Oncol 8(3):173-181. https://doi.org/10.1007/s11523-013-0257-x

26. Bonner JA, Harari PM, Giralt J, Cohen RB, Jones CU, Sur RK, Raben D, Baselga J, Spencer SA, Zhu J, Youssoufian H, Rowinsky EK, Ang KK (2010) Radiotherapy plus cetuximab for locoregionally advanced head and neck cancer: 5 -year survival data from a phase 3 randomised trial, and relation between cetuximabinduced rash and survival. Lancet Oncol 11(1):21-28. https://doi. org/10.1016/S1470-2045(09)70311-0

27. Poprach A, Pavlik T, Melichar B, Puzanov I, Dusek L, Bortlicek Z, Vyzula R, Abrahamova J, Buchler T, Czech Renal Cancer Cooperative G (2012) Skin toxicity and efficacy of sunitinib and sorafenib in metastatic renal cell carcinoma: a national registrybased study. Ann Oncol 23(12):3137-3143. https://doi.org/10. 1093/annonc/mds145

28. Rini BI, Cohen DP, Lu DR, Chen I, Hariharan S, Gore ME, Figlin RA, Baum MS, Motzer RJ (2011) Hypertension as a biomarker of efficacy in patients with metastatic renal cell carcinoma treated with sunitinib. J Natl Cancer Inst 103(9):763-773. https://doi.org/10. 1093/jnci/djr128

29. Hanahan D, Weinberg RA (2011) Hallmarks of cancer: the next generation. Cell 144(5):646-674. https://doi.org/10.1016/j.cell. 2011.02.013

30. Roviello G RA, Fiaschi AI (2016) Apatinib for the treatment of gastric cancer. Expert Rev Gastroenterol Hepatol 10(8):887-892

31. Mi YJ, Liang YJ, Huang HB, Zhao HY, Wu CP, Wang F, Tao LY, Zhang CZ, Dai CL, Tiwari AK, Ma XX, To KK, Ambudkar SV, Chen ZS, Fu LW (2010) Apatinib (YN968D1) reverses multidrug resistance by inhibiting the efflux function of multiple ATP-binding cassette transporters. Cancer Res 70(20):7981-7991. https://doi. org/10.1158/0008-5472.CAN-10-0111

32. Reck M, Bondarenko I, Luft A, Serwatowski P, Barlesi F, Chacko R, Sebastian M, Lu H, Cuillerot JM, Lynch TJ (2013) Ipilimumab in combination with paclitaxel and carboplatin as first-line therapy in extensive-disease-small-cell lung cancer: results from a randomized, double-blind, multicenter phase 2 trial. Ann Oncol 24(1):7583. https://doi.org/10.1093/annonc/mds213

33. Reck M, Luft A, Szczesna A, Havel L, Kim SW, Akerley W, Pietanza MC, Wu YL, Zielinski C, Thomas M, Felip E, Gold K, Horn L, Aerts J, Nakagawa K, Lorigan P, Pieters A, Kong Sanchez T, Fairchild J, Spigel D (2016) Phase III randomized trial of Ipilimumab plus etoposide and platinum versus placebo plus etoposide and platinum in extensive-stage small-cell lung Cancer. J Clin Oncol 34(31):3740-3748. https://doi.org/10.1200/JCO. 2016.67.6601

34. Antonia SJ, Lopez-Martin JA, Bendell J, Ott PA, Taylor M, Eder JP, Jager D, Pietanza MC, Le DT, de Braud F, Morse MA, Ascierto PA, Horn L, Amin A, Pillai RN, Evans J, Chau I, Bono P, Atmaca A, Sharma P, Harbison CT, Lin CS, Christensen O, Calvo E (2016) Nivolumab alone and nivolumab plus ipilimumab in recurrent small-cell lung cancer (CheckMate 032): a multicentre, open-label, 
phase 1/2 trial. Lancet Oncol 17(7):883-895. https://doi.org/10. 1016/S1470-2045(16)30098-5

35. Ott PA, Elez E, Hiret S, Kim DW, Morosky A, Saraf S, Piperdi B, Mehnert JM (2017) Pembrolizumab in patients with extensivestage small-cell lung Cancer: results from the phase Ib KEYNOTE-028 study. J Clin Oncol 35(34):3823-3829. https:// doi.org/10.1200/JCO.2017.72.5069

36. Sequist LV, Chiang A, Gilbert J, Gordon M, Conkling PR, Thompson D, Marcoux JP, Antonia SJ, Liu B, Shames DS, Lopez-Chavez A, O'Hear C, Fasso M, Gettinger S (2016) Clinical activity, safety and predictive biomarkers results from a phase Ia atezolizumab (atezo) trial in extensive-stage small cell lung cancer (ES-SCLC). Ann Oncol 27(6):1425PD. https://doi.org/10.1093/ annonc/mdw389.03

37. Ready N, Owonikoko TK, Postmus PE, Reck M, Peters S, Pieters A, Selvaggi G, Fairchild JP, Govindan R (2017) CheckMate 451: a randomized, double-blind, phase III trial of nivolumab (nivo), nivo plus ipilimumab (ipi), or placebo as maintenance therapy in patients (pts) with extensive-stage disease small cell lung cancer (EDSCLC) after first-line platinum-based doublet chemotherapy (PTDC). J Clin Oncol 34:TPS8579. https://doi.org/10.1200/JCO.2016. 34.15_suppl.TPS8579

38. Gandhi L, Rodriguez-Abreu D, Gadgeel S, Esteban E, Felip E, De Angelis F, Domine M, Clingan P, Hochmair MJ, Powell SF, Cheng SY, Bischoff HG, Peled N, Grossi F, Jennens RR, Reck M, Hui R, Garon EB, Boyer M, Rubio-Viqueira B, Novello S, Kurata T, Gray JE, Vida J, Wei Z, Yang J, Raftopoulos H, Pietanza MC, Garassino MC, Investigators K- (2018) Pembrolizumab plus chemotherapy in metastatic non-small-cell lung cancer. N Engl J Med 378 (22): 2078-2092. https://doi.org/10.1056/NEJMoa1801005

39. Paz-Ares L, Luft A, Vicente D, Tafreshi A, Gumus M, Mazieres J, Hermes B, Cay Senler F, Csoszi T, Fulop A, Rodriguez-Cid J, Wilson J, Sugawara S, Kato T, Lee KH, Cheng Y, Novello S, Halmos B, Li X, Lubiniecki GM, Piperdi B, Kowalski DM, Investigators K- (2018) Pembrolizumab plus chemotherapy for squamous non-small-cell lung cancer. N Engl J Med 379 (21): 2040-2051. https://doi.org/10.1056/NEJMoa1810865

40. Parikh M, Pan CX, Beckett LA, Li Y, Robles DA, Aujla PK, Lara PN Jr (2018) Pembrolizumab combined with either docetaxel or gemcitabine in patients with advanced or metastatic platinumrefractory urothelial Cancer: results from a phase I study. Clin Genitourin Cancer 16(6):421-428 e421. https://doi.org/10.1016/j. clgc.2018.07.004

41. Bang YJ, Kang YK, Catenacci DV, Muro K, Fuchs CS, Geva R, Hara H, Golan T, Garrido M, Jalal SI, Borg C, Doi T, Yoon HH, Savage MJ, Wang J, Dalal RP, Shah S, Wainberg ZA, Chung HC (2019) Pembrolizumab alone or in combination with chemotherapy as first-line therapy for patients with advanced gastric or gastroesophageal junction adenocarcinoma: results from the phase II nonrandomized KEYNOTE-059 study. Gastric Cancer 22:828837. https://doi.org/10.1007/s10120-018-00909-5

42. Reck M, Rodriguez-Abreu D, Robinson AG, Hui R, Csoszi T, Fulop A, Gottfried M, Peled N, Tafreshi A, Cuffe S, O'Brien M, Rao S, Hotta K, Leiby MA, Lubiniecki GM, Shentu Y, Rangwala R, Brahmer JR, Investigators K- (2016) Pembrolizumab versus chemotherapy for PD-L1-positive non-small-cell lung cancer. N Engl J Med 375 (19):1823-1833. https://doi.org/10.1056/ NEJMoa1606774

43. Brahmer JR, Rodriguez-Abreu D, Robinson AG, Hui R, Csõszi T, Fülöp A, Gottfried M, Peled N, Tafreshi A, Cuffe S, O'Brien M, Rao S, Hotta K, Leiby MA, McLean J, Shentu Y, Rangwala RA, Reck M (2017) Progression after the next line of therapy (PFS2) and updated OS among patients (pts) with advanced NSCLC and PD-L1 tumor proportion score (TPS) $\geq 50 \%$ enrolled in KEYNOTE-024. J Clin Oncol 35:9000. https://doi.org/10.1200/ JCO.2017.35.15_suppl.9000

Publisher's note Springer Nature remains neutral with regard to jurisdictional claims in published maps and institutional affiliations. 